\title{
Use of chloroquine in reducing mother to child transmission of HIV-I during breastfeeding
}

Marloes Naarding ${ }^{1}$, Stanley Luchters ${ }^{2}$, Joseph Vyankandondera ${ }^{3}$, Ferdinand Wit ${ }^{2}$, Nienke Veldhuijzen ${ }^{2}$, Brigitte Kankindi' ${ }^{3}$, Rolf Sparidans ${ }^{4}$, Jos Beijnen ${ }^{4}$, Georgios Pollakis ${ }^{1}$, Johan Boelaert ${ }^{5}$, Joep Lange ${ }^{2}$ and William Paxton*1

Address: ${ }^{1}$ Academic Medical Center, University of Amsterdam, Amsterdam, Netherlands, ${ }^{2}$ International Antiviral Therapy Evaluation Center, Amsterdam, Netherlands, ${ }^{3}$ Centre Hospitalier Universitaire de Kigali, Kigali, Rwanda, ${ }^{4}$ University of Utrecht, Utrecht, Netherlands and ${ }^{5}$ Algemeen Ziekenhuis St-Jan, Brugge, Belgium

* Corresponding author

from Fifth Dominique Dormont International Conference. Mother-to-child transmitted viral diseases: from transmission to children care Paris, France. 26-28 March 2009

Published: 22 July 2009

Retrovirology 2009, 6(SuppI I):OI3 doi:I0.II86/I742-4690-6-SI-OI3

This abstract is available from: http://www.retrovirology.com/content/6/SI/OI3

(c) 2009 Naarding et al; licensee BioMed Central Ltd.

Chloroquine (CQ) has been shown to inhibit HIV-1 replication in vitro as well as in vivo, thereby indicating its use as an effective drug in limiting mother to child transmission of HIV-1 during breastfeeding. We show that HIV-1 replication on $\mathrm{CD} 4^{+}$-T-lymphocytes can be reduced in the presence of CQ and show that the reduced replication is producer cell specific and that viruses generated in the presence of CQ are not inhibited for their subsequent infectivity and replication. By analysing the gp120 envelope protein sequences from virus passaged over a long period of time in the presence or absence of CQ we demonstrate variant evolution patterns of the envelope. We also demonstrate that HIV-1 produced in the presence of CQ have a reduced capacity for the transfer by Raji-DCSIGN cells to CD4+ T-lymphocytes indicating another means whereby virus replication may be reduced in vivo. We conducted a Phase I/II, randomized, placebo-controlled study to evaluate chloroquine (CQ) administration to reduce HIV-1 RNA levels in human milk. Thirty HIV-1 positive pregnant Rwandese women (CQ $n=20$; placebo $\mathrm{n}=10$ ) were enrolled in a 16 week study, with the treatment group receiving a $200 \mathrm{mg}$ oral dose of CQ daily. Base-line plasma viral load (pVL) measurements and CD4 counts were determined prior to delivery with $\mathrm{pVL}$, breast milk VL (bmVL) and CQ levels measured at wk0, wk8 and wk16. For selected mothers the envelope C1C4 gp120 region was DNA sequenced and analyzed. A higher concentration of CQ in breast milk compared to plasma (over 2.5 fold) was observed after 8 and 16 weeks of treatment. CQ levels in plasma correlated to those in the left and right breast milk ( $\mathrm{P}=0.002$ and $\mathrm{P}=0.003$, respectively). Additionally, a link between high CQ concentrations in plasma and high CD4 counts $(\mathrm{P}<0.001)$ was observed. No alterations in bmVL were observed with CQ treatment whilst $\mathrm{pVL}$ increased significantly $(P=0.001)$. In over half of the CQ treated individuals there was a greater than 5 fold increase in pVL which was observed by week 8 of treatment. No specific alterations in the gp120 envelope sequences could be associated with CQ treatment. Our results indicate that CQ administration is associated with increased $\mathrm{pVL}$ in early breastfeeding mothers from Rwanda which cautions against the use of CQ in such individuals. 